\title{
Desempenho produtivo de ovelhas acasaladas no verão e no outono recebendo ou não suplementação alimentar durante o acasalamento ${ }^{1}$
}

\section{Productive performance of ewes in summer or autumn mating seasons, and receiving or not food suplementation during the mating period}

\author{
Edson Luis de Azambuja Ribeiro ${ }^{2 *}$; Leandro das Dores Ferreira da Silva²; Ivone \\ Yurika Mizubuti²; Marco Antonio da Rocha²; Adriana Pereira da Silva ${ }^{3}$; Rinaldo \\ Masato Mori ${ }^{4}$; Danilo Otávio Laurenti Ferreira ${ }^{5}$ Tiago Rodrigues Casimiro ${ }^{5}$
}

Resumo

\begin{abstract}
Este trabalho teve como principais objetivos avaliar o desempenho de ovelhas de diferentes grupos genéticos quando acasaladas no verão ou no outono, bem como o efeito da suplementação alimentar por 14 dias antes e durante o período de acasalamento. Foram utilizadas 76 ovelhas, com idade variando de 2 a 8 dentes, dos grupos genéticos Corriedale, Hampshire Down, Ile de France e Suffolk. Apesar de ter ocorrido maiores ganhos de peso no acasalamento de verão e para as ovelhas suplementadas, estas diferenças não se traduziram em maior desempenho reprodutivo. A produtividade, expressa como quilos de cordeiros desmamados por quilo de ovelha acasalada, foi similar nos acasalamentos de verão e outono $(0,27$ e 0,26$)$ e para ovelhas recebendo ou não suplementação alimentar $(0,27$ e 0,26$)$. Os outros efeitos avaliados (idade das ovelhas, grupo genético, tipo de parto e o sexo dos cordeiros) também não afetaram este índice de produtividade. Portanto, havendo boa condição de pastagem não há necessidade de suplementação alimentar antes e durante a monta, podendo ser utilizada a estação de acasalamento de verão ou outono, no norte do Paraná.

Palavras-chave: Estação de Monta; Flushing; Grupo Genético; Ovinos; Raças; Reprodução.
\end{abstract}

\begin{abstract}
This work had as objectives to evaluate the performance of ewes from different genetic groups when mated in summer or autumn, and receiving or not food supplementation from 14 days before and during the mating season. Seventy-six ewes from the genetic groups Corriedale, Hampshire Down, Ile de France and Suffolk, with ages varying from 2 to 8 teeth, were used. Although greater weight gains occurred in the summer mating and in ewes receiving food supplementation, these differences did not enhance the reproductive performance of these animals. Productivity expressed as $\mathrm{kg}$ of weaned lambs $/ \mathrm{kg}$ of joined ewes was similar for summer and autumn mating ( 0.27 and 0.26$)$, and for ewes receiving or not food supplementation ( 0.27 and 0.26 ). The other evaluated effects, age of ewe, genetic group, type of lambing (single or twins) and sex of lambs, did not affect this productivity index. It can be concluded that in good pasture conditions, there is no need for food supplementation before and during the mating season. At the same way, it can be used summer or autumn mating seasons in the northern region of the Paraná state.
\end{abstract}

Key words: Breeds; Flushing; Genetic Group; Mating Season; Reproduction; Sheep

\footnotetext{
${ }^{1}$ Apoio Financeiro: CNpq e CPG/UEL.

${ }^{2}$ Professores do Departamento de Zootecnia da Universidade Estadual de Londrina- PR.

${ }^{3}$ Engenheira Agrônoma.

${ }^{4}$ Aluno do Curso de Pós-Graduação em Ciência Animal da UEL.

${ }^{5}$ Alunos do Curso de Medicina Veterinária da UEL.

* Autor para correspondência.
} 


\section{Introdução}

A adoção de práticas de manejo capazes de melhorar o desempenho reprodutivo dos ovinos é de suma importância, já que um dos graves problemas da ovinocultura no Brasil é o baixo desempenho ocasionado pela falta de um manejo mais adequado aos rebanhos. A melhoria dos índices reprodutivos geralmente resulta em maior lucratividade na exploração ovina, tendo-se mais animais para venda e possibilitando maior pressão de seleção, substituindose os menos produtivos (SELAIVE-VILLARROEL, 1984; BRADFORD, 1985; ELSEN et al., 1994).

Significativo aumento de natalidade pode ser obtido através do adequado manejo das fêmeas antes e durante o acasalamento (COIMBRA FILHO, 1997). Segundo Siqueira (1990), duas a três semanas antes do início do acasalamento e durante o mesmo, deve-se melhorar o nível nutricional, possibilitando ganho de peso e, consequentemente, taxas de concepção mais elevadas. Esta prática de suplementação alimentar é normalmente conhecida como "flushing". Este ganho de peso adicional se traduz em alta apresentação de cios no momento de entrada dos carneiros e aumento da taxa ovulatória, aumentando em decorrência as taxas de fertilidade e prolificidade (SELAIVE-VILLARROEL, 1986).

O aumento de nutrientes eleva a taxa de ovulação. O mecanismo desse efeito não foi ainda totalmente esclarecido, mas acredita-se que maior aporte de nutrientes leve a maior resposta hormonal. Coop (1966 apud THOMAS et al., 1987), comenta que a maior ingestão de nutrientes imediatamente antes da monta, leva a uma maior atividade de enzimas metabolizadoras de esteróides circulantes. Com a diminuição desses esteróides, que inibem a atividade da pituitária, há maior secreção de gonadotropinas pituitárias, aumentando a taxa ovulatória. Boukhliq, Adams e Martin, (1996) concluíram que a nutrição altera o balanço entre a secreção de FSH (hormônio folículo-estimulante) pela pituitária e o "feedback" gonadal pela mudança de responsividade aos efeitos inibitórios do estradiol e inibina.
A época de acasalamento é um outro fator importante no manejo do rebanho. As ovelhas são consideradas, de maneira geral, poliestras estacionais, isto é, só apresentam cios durante um determinado período do ano. Contudo, nas diferentes raças ovinas não há uniformidade quanto ao início e duração da estação reprodutiva (MINOLA; GOYENECHEA, 1975; COIMBRA FILHO, 1997).

Segundo Ortoloni e Siqueira (1986), nas raças nacionais o cio ocorre durante o ano inteiro, a cada 16 ou 18 dias. Nas raças importadas, o cio só ocorre numa determinada época do ano, estando em geral relacionado à melhoria das pastagens e também na mudança de estação, do verão para o outono, devido à diminuição da luminosidade diária. Vários experimentos conduzidos no Rio Grande do Sul com raças laníferas ou de duplo propósito, mostraram melhores desempenhos reprodutivos nos acasalamentos de outono, com marcado período de anestro no inverno e primavera (MIES FILHO; RAMOS, 1960; NUNES; FIGUEIRÓ, 1975; SILVA; FIGUEIRÓ, 1980; BASILE; MIES FILHO; SELAIVE-VILLARROEL，1985). No norte do Paraná, em um rebanho Hampshire Down com monta contínua, Ribeiro et al. (1996) observaram coberturas em todas as estações do ano, porém neste e em um outro rebanho da mesma raça (RIBEIRO et al., 1999) a maior atividade sexual foi observada nos meses de verão e outono.

De acordo com Mies Filho e Ramos (1987), a raça influi na maior ou menor dilatação do período de funcionamento sexual. No Brasil, classificam-se certas raças como precoces (Merino), por apresentarem cios em dezembro, e outras como tardias (Romney Marsh), por entrarem em atividade sexual praticamente em março. Em um nível intermediário há a raça Corriedale, que apresenta maior frequiência de cios em fevereiro. Tal situação não pode ser vista no sentido absoluto, existindo ocorrência de cios nas raças citadas em períodos diversos.

As diferenças raciais nada mais representam que um modo peculiar de reação de cada uma delas ao estímulo que controla fundamentalmente o estabe- 
lecimento da estação sexual. O principal fator que controla o período reprodutivo são as mudanças de duração dos dias (fotoperíodo), que é função basicamente da relação horas luz/horas escuridão (SELAIVE-VILLARROEL, 1986; MIES FILHO ; RAMOS, 1987). Hafez (1952 apud MIES FILHO; RAMOS, 1987), demonstrou maior efetividade reprodutiva quando o regime lumínico obedeceu ao ritmo de 8 horas de luz e 16 horas de escuridão.

Para se determinar qual a melhor época de acasalamento, deve ser levado também em consideração, a melhor época de parição. Com o acasalamento nos meses de novembro e dezembro, as ovelhas se beneficiam de boas pastagens, contando com uma nutrição adequada para o desenvolvimento do feto. A parição se dará em abril-maio (outono), antes da chegada do inverno, causador de grande mortalidade nos recém-nascidos (ORTOLANI; SIQUEIRA, 1986). De acordo com Villas Boas (1990), a estação de acasalamento feita no verão faz com que os nascimentos ocorram no inverno quando há menor incidência de bicheiras nos cordeiros e ovelhas, embora sempre existam riscos de mortes dos cordeiros devido ao frio. Por outro lado, com acasalamentos em março-abril e parições em agosto-setembro, afasta-se o perigo de frios mais intensos e as lactantes amamentam melhor os filhos, devido à recuperação das pastagens na primavera (SILVA; FIGUEIRÓ, 1980; ORTOLANI; SIQUEIRA, 1986), além de ser a época (outono) de melhor desempenho reprodutivo.

Segundo Selaive-Villarroel (1979), o estado nutricional da ovelha na parição determinará em grande parte o tamanho e vigor do cordeiro ao nascer. O peso dos cordeiros é o maior responsável por sua capacidade de sobrevivência, principalmente quando as condições ambientais no momento do nascimento são adversas. Assim, por exemplo, os cordeiros nascidos como gêmeos apresentam maior porcentagem de mortalidade, devido principalmente ao seu menor peso corporal quando comparado com cordeiros únicos.
Este trabalho teve como principais objetivos avaliar os efeitos do acasalamento de verão ou de outono, bem como a utilização de suplementação alimentar, sobre o desempenho reprodutivo e produtivo de ovelhas de diferentes grupos genéticos no norte do Paraná.

\section{Material e Métodos}

O experimento foi conduzido na Fazenda Escola da Universidade Estadual de Londrina, situada no município de Londrina, Paraná. As coordenadas geográficas do município são de $23^{\circ} 23^{\prime} \mathrm{S}$ de latitude e $51^{\circ} 11^{\prime} \mathrm{W}$ de longitude, a altitude média de 566 metros e o clima, segundo Koeppen, é do tipo Cfa (Subtropical úmido). A temperatura média anual é de $21,9^{\circ} \mathrm{C}$, com média em torno de $16,7^{\circ} \mathrm{C}$ nos meses mais frios do ano (Junho e Julho) e média de $23,9^{\circ} \mathrm{C}$ no mês mais quente do ano (Fevereiro). A precipitação total pluviométrica anual é de $1615 \mathrm{~mm}$ (CORRÊA; GODOY; BERNARDES,1982).

Foram utilizadas 12 ovelhas Corriedale, 40 ovelhas Hampshire Down, 16 ovelhas Ile de France e oito ovelhas Suffolk, com idades de 2 a 8 dentes. As ovelhas Corriedale eram de raça definida e as ovelhas dos demais grupos genéticos possuíam grau sanguíneo variado. Os animais foram distribuídos ao acaso, segundo o grupo genético e a idade, em uma das duas épocas de acasalamento (verão ou outono) e em um dos dois níveis de suplementação alimen$\operatorname{tar}$ (sim e não). Os períodos de acasalamento duraram 45 dias cada, iniciando em 23 de dezembro e encerrando em 6 de fevereiro para o acasalamento de verão, e no outono, de 15 de março a 30 de abril. As ovelhas foram acasaladas com carneiros de suas próprias raças, com exceção das ovelhas Corriedales que foram acasaladas com carneiros Suffolk e Ile de France. Foram utilizados dois carneiros de cada grupo genético.

O nível de suplementação alimentar "sim" correspondia a $0,5 \mathrm{~kg}$ de milho grão triturado por animal/dia, e o nível "não" a ausência de suplementação. A suplementação iniciou 14 dias antes da estação de 
acasalamento e terminou no final da mesma. Durante todo o período experimental os animais foram mantidos em pastagem de grama Coast-Cross (Cynodon dactylon (L.) Pers) e tiveram água e sal mineralizado à vontade. Todos os animais foram vermifugados 14 dias antes dos períodos de acasalamento, e posteriormente de acordo com exame de fezes.

As variáveis medidas foram os pesos das ovelhas no início da suplementação (14 dias antes do acasalamento), no início e final da estação de monta, e dentro das primeiras 24 horas após o parto; os pesos dos cordeiros ao nascimento e aos 70 dias de idade (desmame); ganhos de peso até o final da monta para as ovelhas e do nascimento ao desmame para os cordeiros. Foram, também, medidos os índices de prolificidade (número de cordeiros por ovelha) ao parto e ao desmame, as taxas de parição (ovelhas paridas em relação a ovelhas acasaladas), de partos gemelares (partos gemelares em relação ao total de partos) e mortalidade dos cordeiros (cordeiros mortos em relação ao total nascido), e os índices de produtividade: $\mathrm{kg}$ de cordeiros desmamados por $\mathrm{kg}$ de ovelha acasalada e $\mathrm{kg}$ de cordeiros desmamados por $\mathrm{kg}$ de ovelhas paridas.

Os dados obtidos foram submetidos à análise de variância através do pacote estatístico SAS (SAS Institute, 1994). Na análise dos pesos, ganhos de peso e prolificidade das ovelhas foram levados em consideração os efeitos de época de acasalamento (verão e outono), nível de suplementação (sim e não), idade $(02,04,06$ e 08 dentes) e grupo genético (Corriedale, Hampshire Down, Ile de France e Suffolk). Para os índices de produtividade, bem como para os pesos e ganhos de peso médio diário dos cordeiros, foram incluídos os efeitos de tipo de parto (simples e gemelar) e sexo do cordeiro (fêmea e macho). Por não apresentarem significância estatística, as interações duplas entre os efeitos foram desconsideradas no modelo final. As taxas de parição, partos gemelares e mortalidade dos cordeiros foram analisadas pelo teste do qui-quadrado. As diferenças entre médias foram testadas pelo teste $\mathrm{t}$ ao nível de $5 \%$ de probabilidade.

\section{Resultados e Discussão}

Na Tabela 1 são apresentados os resultados para os pesos das ovelhas, onde pode se observar que não houve diferença $(\mathrm{P}>0,05)$ para os pesos no início do experimento (início da suplementação ou 14 dias antes do acasalamento), início e final da monta e ao parto entre as ovelhas acasaladas no verão e outono, e entre ovelhas suplementadas ou não com $0,5 \mathrm{~kg}$ de milho grão por dia.

Tabela 1 - Médias dos pesos $(\mathrm{kg})$ das ovelhas aos 14 dias antes da estação de acasalamento (início da suplementação), no início e final do acasalamento e ao parto, de acordo com a época de acasalamento, com o nível de suplementação alimentar, a idade e o grupo genético.

\begin{tabular}{|c|c|c|c|c|}
\hline Efeitos & $\begin{array}{c}\text { Peso - Início } \\
\text { Suplementação }\end{array}$ & $\begin{array}{l}\text { Peso - Início } \\
\text { Acasalamento }\end{array}$ & $\begin{array}{l}\text { Peso - Final } \\
\text { Acasalamento }\end{array}$ & Peso - Parto \\
\hline \multicolumn{5}{|l|}{ Época } \\
\hline Verão & $44,7 \pm 1,5$ & $48,5 \pm 1,4$ & $51,7 \pm 1,5$ & $50,8 \pm 1,8$ \\
\hline Outono & $46,4 \pm 1,4$ & $46,8 \pm 1,4$ & $51,3 \pm 1,4$ & $49,2 \pm 1,6$ \\
\hline $\operatorname{Pr}>\mathrm{F}$ & 0,2978 & 0,2931 & 0,8082 & 0,4069 \\
\hline \multicolumn{5}{|l|}{ Suplementação } \\
\hline Não & $46,9 \pm 1,4$ & $48,7 \pm 1,4$ & $51,2 \pm 1,4$ & $50,0 \pm 1,7$ \\
\hline Sim & $44,2 \pm 1,4$ & $46,6 \pm 1,4$ & $51,9 \pm 1,5$ & $50,0 \pm 1,7$ \\
\hline $\operatorname{Pr}>\mathrm{F}$ & 0,1018 & 0,1863 & 0,6400 & 0,9975 \\
\hline \multicolumn{5}{|l|}{ Idade - dentes } \\
\hline 02 & $37,3 \pm 1,6 \mathrm{c}$ & $39,3 \pm 1,6 \mathrm{c}$ & $43,2 \pm 1,6 b$ & $42,0 \pm 2,0 \mathrm{~b}$ \\
\hline 04 & $43,6 \pm 2,5 b$ & $46,5 \pm 2,4 b$ & $50,8 \pm 2,5 \mathrm{a}$ & $50,0 \pm 2,8 \mathrm{a}$ \\
\hline 06 & $50,0 \pm 2,3 \mathrm{a}$ & $52,1 \pm 2,3 \mathrm{ab}$ & $55,8 \pm 2,3 \mathrm{a}$ & $53,2 \pm 2,7 \mathrm{a}$ \\
\hline 08 & $51,3 \pm 1,5 \mathrm{a}$ & $52,7 \pm 1,5 \mathrm{a}$ & $56,3 \pm 1,5 \mathrm{a}$ & $54,8 \pm 1,7 \mathrm{a}$ \\
\hline $\operatorname{Pr}>F$ & 0,0001 & 0,0001 & 0,0001 & 0,0001 \\
\hline \multicolumn{5}{|l|}{ Grupo } \\
\hline Corriedale & $38,6 \pm 2,2 \mathrm{c}$ & $40,6 \pm 2,2 \mathrm{c}$ & $44,2 \pm 2,3 \mathrm{c}$ & $41,7 \pm 2,9 \mathrm{c}$ \\
\hline Hampshire & $44,1 \pm 1,2 b$ & $46,4 \pm 1,2 b$ & $49,9 \pm 1,2 b$ & $49,6 \pm 1,3 b$ \\
\hline Ile de France & $46,8 \pm 1,9 \mathrm{ab}$ & $48,2 \pm 1,8 \mathrm{ab}$ & $52,8 \pm 1,9 \mathrm{ab}$ & $48,9 \pm 2,1 b c$ \\
\hline Suffolk & $52,7 \pm 3,2 \mathrm{a}$ & $55,4 \pm 3,2 \mathrm{a}$ & $59,2 \pm 3,3$ a & $59,8 \pm 3,8$ a \\
\hline $\operatorname{Pr}>\mathrm{F}$ & 0,0029 & 0,0018 & 0,0019 & 0,0025 \\
\hline
\end{tabular}

Estes resultados aparentemente discrepantes, principalmente no que diz respeito a animais suplementados ou não, não ocorreu devido à diferença, apesar de não significativa, de 2,7 kg no início do experimento a favor das ovelhas não suplementadas, já que como observado na Tabela 2, as ovelhas suplementadas ganharam significativa- 
mente mais peso do início da suplementação ou do início do acasalamento até o final do mesmo. Como resultado do ganho de peso, no final da monta e no parto, a diferença no peso inicial entre ovelhas, suplementadas ou não, desapareceu.

Tabela 2 - Médias para ganhos de peso (kg) das ovelhas do início da suplementação (14 dias antes da estação de acasalamento) ao início da estação de acasalamento (IS-IA), do início ao final do acasalamento (IA-FA) e do início da suplementação ao final do acasalamento (IS-FA), de acordo com a época de acasalamento, com o nível de suplementação alimentar, a idade e o grupo genético.

\begin{tabular}{|c|c|c|c|}
\hline \multirow[b]{2}{*}{ Efeitos } & \multicolumn{3}{|c|}{ Ganhos de peso } \\
\hline & IS-IA & IA-FA & IS-FA \\
\hline \multicolumn{4}{|l|}{ Época } \\
\hline Verão & $3,8 \pm 0,4 \mathrm{a}$ & $3,3 \pm 0,5 b$ & $7,0 \pm 0,5 \mathrm{a}$ \\
\hline Outono & $0,4 \pm 0,3 b$ & $4,5 \pm 0,5 \mathrm{a}$ & $4,9 \pm 0,5 b$ \\
\hline $\operatorname{Pr}>F$ & 0,0001 & 0,0257 & 0,0001 \\
\hline \multicolumn{4}{|l|}{ Suplementação } \\
\hline Não & $1,8 \pm 0,3$ & $2,4 \pm 0,5 b$ & $4,2 \pm 0,5 b$ \\
\hline Sim & $2,4 \pm 0,4$ & $5,4 \pm 0,5 \mathrm{a}$ & $7,7 \pm 0,5 \mathrm{a}$ \\
\hline $\operatorname{Pr}>F$ & 0,1590 & 0,0001 & 0,0001 \\
\hline \multicolumn{4}{|l|}{ Idade - dentes } \\
\hline 02 & $2,0 \pm 0,4$ & $3,9 \pm 0,5$ & $5,9 \pm 0,6$ \\
\hline 04 & $2,9 \pm 0,6$ & $4,3 \pm 0,9$ & $7,2 \pm 0,9$ \\
\hline 06 & $2,1 \pm 0,6$ & $3,7 \pm 0,8$ & $5,8 \pm 0,9$ \\
\hline 08 & $1,4 \pm 0,4$ & $3,6 \pm 0,5$ & $5,1 \pm 0,6$ \\
\hline $\operatorname{Pr}>F$ & 0,2509 & 0,9235 & 0,3084 \\
\hline \multicolumn{4}{|l|}{ Grupo } \\
\hline Corriedale & $2,0 \pm 0,5$ & $3,7 \pm 0,8$ & $5,6 \pm 0,8$ \\
\hline Hampshire & $2,2 \pm 0,3$ & $3,5 \pm 0,4$ & $5,8 \pm 0,4$ \\
\hline Ile de France & $1,4 \pm 0,5$ & $4,6 \pm 0,7$ & $6,0 \pm 0,7$ \\
\hline Suffolk & $2,7 \pm 0,8$ & $3,8 \pm 1,1$ & $6,5 \pm 1,2$ \\
\hline $\operatorname{Pr}>F$ & 0,3890 & 0,5939 & 0,9354 \\
\hline
\end{tabular}

$\mathrm{a}, \mathrm{b}, \mathrm{c}-(\mathrm{P}<0,05)$
Em relação à idade das ovelhas, a principal diferença observada foi o menor peso $(\mathrm{P}<0,05)$ das borregas de 2 dentes, fato este esperado por serem animais ainda não completamente desenvolvidos. Ovelhas do grupo genético Corriedale foram mais leves $(\mathrm{P}<0,05)$ em todas as pesagens e as ovelhas Suffolk as mais pesadas. As ovelhas Ile de France e Hampshire Down apresentaram pesos intermediários e parecidos (Tabela 1). Roda et al. (1993) observaram uma diferença ao redor de 5,0 $\mathrm{kg}$ a mais para ovelhas Suffolk comparadas com ovelhas Corriedale na cobertura.

Do início da suplementação ao final da estação de acasalamento, as ovelhas acasaladas no verão ganharam $(\mathrm{P}<0,05)$ mais peso, provavelmente em função de uma maior qualidade e disponibilidade da pastagem neste período. Por outro lado, não foram observadas diferenças $(\mathrm{P}>0,05)$ nos ganhos de peso entre as diferentes idades e grupos genéticos (Tabela 2).

Dados de desempenho reprodutivo e de mortalidade dos cordeiros são apresentados nas Tabelas $3 \mathrm{e}$ 4. Pode ser observado que ocorreram diferenças $(\mathrm{P}<0,05)$ entre os grupos genéticos para taxas de partos gemelares e mortalidade dos cordeiros. Da mesma forma, houve diferença $(\mathrm{P}<0,05)$ na mortalidade entre tipos de parto e sexo dos cordeiros (Tabela 3). 
Tabela 3 - Médias para taxas de parição, partos gemelares e mortalidade dos cordeiros até o desmame, de acordo com a época de acasalamento, com o nível de suplementação alimentar, a idade, o grupo genético, o tipo de parto e o sexo dos cordeiros.

\begin{tabular}{|c|c|c|c|}
\hline Efeitos & $\begin{array}{c}\text { Parição } \\
(\%)\end{array}$ & $\begin{array}{c}\text { Partos Gemelares } \\
(\%)\end{array}$ & $\begin{array}{c}\text { Mortalidade } \\
(\%)\end{array}$ \\
\hline \multicolumn{4}{|l|}{ Época } \\
\hline Verão & 81,08 & 23,33 & 18,42 \\
\hline Outono & 94,87 & 10,81 & 12,20 \\
\hline $\operatorname{Pr}>\mathrm{F}$ & 0,0629 & 0,1688 & 0,4411 \\
\hline \multicolumn{4}{|l|}{ Suplementação } \\
\hline Não & 92,31 & 13,89 & 9,76 \\
\hline Sim & 83,78 & 19,35 & 21,05 \\
\hline $\operatorname{Pr}>\mathrm{F}$ & 0,2503 & 0,5470 & 0,1622 \\
\hline \multicolumn{4}{|l|}{ Idade - dentes } \\
\hline 02 & 83,33 & 0,00 & 5,00 \\
\hline 04 & 90,91 & 10,00 & 9,09 \\
\hline 06 & 83,33 & 20,00 & 8,33 \\
\hline 08 & 93,10 & 29,63 & 25,00 \\
\hline $\operatorname{Pr}>\mathrm{F}$ & 0,6681 & 0,0513 & 0,1677 \\
\hline \multicolumn{4}{|l|}{ Grupo } \\
\hline Corriedale & 76,92 & $30,00 \mathrm{~b}$ & $30,77 \mathrm{bc}$ \\
\hline Hampshire & 92,50 & $5,41 \mathrm{a}$ & $5,13 \mathrm{a}$ \\
\hline Ile de France & 93,75 & $20,00 \mathrm{ab}$ & $11,11 \mathrm{ab}$ \\
\hline Suffolk & 71,43 & $60,00 \mathrm{~b}$ & $44,44 \mathrm{c}$ \\
\hline $\operatorname{Pr}>\mathrm{F}$ & 0,1993 & 0,0086 & 0,0084 \\
\hline \multicolumn{4}{|l|}{ Tipo parto } \\
\hline Simples & - & - & $3,57 \mathrm{a}$ \\
\hline Gemelares & - & - & $43,48 \mathrm{~b}$ \\
\hline $\operatorname{Pr}>\mathrm{F}$ & - & - & 0,0001 \\
\hline \multicolumn{4}{|l|}{ Sexo } \\
\hline Fêmea & - & - & $22,73 \mathrm{~b}$ \\
\hline Macho & - & - & $5,71 \mathrm{a}$ \\
\hline $\operatorname{Pr}>\mathrm{F}$ & - & - & 0,0364 \\
\hline
\end{tabular}

$\mathrm{a}, \mathrm{b}-(\mathrm{P}<0,05)$

As percentagens de partos gemelares apresentaram valores crescentes com a idade e se mostraram quase significativos $(\mathrm{P}=0,0513)$, onde as ovelhas de 8 dentes apresentaram $9,6 \%$ mais partos gemelares que as ovelhas de 6 dentes, e estas $10 \%$ mais do que as de 4 dentes, sendo que as ovelhas de 4 dentes apresentaram $10 \%$ de partos gemelares e as de 2 dentes não apresentaram partos gemelares. Menor taxa de parição não foi observada no presente trabalho $(\mathrm{P}>0,05)$, onde borregas e ovelhas de 8 dentes apresentaram taxas de $83,33 \%$ e $93,10 \%$, respectivamente. Porém, para prolificidade (Tabela 4) foi observada diferença $(\mathrm{P}<0,05)$ entre as idades, onde as ovelhas de 2 dentes apresentaram menor número de cordeiros ao parto em relação as ovelhas de 8 dentes, sendo que as de 4 e 6 dentes apresentaram valores intermediários. Estes resultados concordam em parte com as afirmações de Minola e Goyenechea (1975), em que as borregas além de apresentar uma menor taxa ovulatória, e por consequiência menor percentagem de partos gemelares e prolificidade, também apresentam menor percentagem de parição.

Tabela 4 - Médias para prolificidade das ovelhas ao parto e ao desmame de acordo com a época de acasalamento, o nível de suplementação alimentar, a idade e o grupo genético.

\begin{tabular}{|c|c|c|}
\hline Efeitos & Prolificidade ao parto & Prolificidade ao desmame \\
\hline \multicolumn{3}{|l|}{ Época } \\
\hline Verão & $1,03 \pm 0,10$ & $0,76 \pm 0,09$ \\
\hline Outono & $1,09 \pm 0,10$ & $0,86 \pm 0,09$ \\
\hline $\operatorname{Pr}>\mathrm{F}$ & 0,5942 & 0,3386 \\
\hline \multicolumn{3}{|l|}{ Suplementação } \\
\hline Não & $1,08 \pm 0,10$ & $0,88 \pm 0,09$ \\
\hline Sim & $1,03 \pm 0,10$ & $0,74 \pm 0,09$ \\
\hline $\operatorname{Pr}>\mathrm{F}$ & 0,6871 & 0,2000 \\
\hline \multicolumn{3}{|l|}{ Idade - dentes } \\
\hline 02 & $0,83 \pm 0,12 b$ & $0,71 \pm 0,10$ \\
\hline 04 & $0,96 \pm 0,18 \mathrm{ab}$ & $0,72 \pm 0,15$ \\
\hline 06 & $1,10 \pm 0,17 \mathrm{ab}$ & $0,86 \pm 0,14$ \\
\hline 08 & $1,36 \pm 0,11 \mathrm{a}$ & $0,97 \pm 0,09$ \\
\hline $\operatorname{Pr}>\mathrm{F}$ & 0,0132 & 0,2502 \\
\hline \multicolumn{3}{|l|}{ Grupo } \\
\hline Corriedale & $0,78 \pm 0,17$ & $0,58 \pm 014$ \\
\hline Hampshire & $0,95 \pm 0,09$ & $0,90 \pm 0,08$ \\
\hline Ile de France & $1,21 \pm 0,14$ & $1,05 \pm 0,12$ \\
\hline Suffolk & $1,30 \pm 0,21$ & $0,73 \pm 0,18$ \\
\hline $\mathrm{PR}>\mathrm{F}$ & 0,1135 & 0,0800 \\
\hline
\end{tabular}

$\mathrm{a}, \mathrm{b}-(\mathrm{P}<0,05)$ 
As ovelhas Suffolk apresentaram as maiores taxas de partos gemelares, porém não diferiram das Corriedale e Ile de France, e as Hampshire Down apresentaram o menor valor. De maneira inversa, as ovelhas Hampshire Down e Ile de France apresentaram as menores taxas de mortalidade dos cordeiros, provavelmente em função do menor número de gêmeos observado nestas raças. Este fato é comprovado pela comparação entre os tipos de parto, onde os cordeiros nascidos como gêmeos apresentaram uma maior mortalidade (Tabela 3). Estes resultados concordam com Roda et al. (1990), que encontraram maior taxa de mortalidade em cordeiros nascidos como gêmeos nas raças Corriedale e Ideal. Também Roda; Santos; Cunha,. (1995) observaram maior mortalidade pré-desmame em cordeiros que tiveram menores pesos ao nascimento. A maior mortalidade das fêmeas em relação aos machos, não tem uma explicação, pois não houve diferenças no peso ao nascer e no ganho de peso entre os sexos (Tabela 5).

Outro resultado bastante interessante e que aproximou a significância, é a maior taxa de parição $(\mathrm{P}<0,07)$ observada no acasalamento de outono, concordando com diversos autores (MIES FILHO; RAMOS, 1960; NUNES; FIGUEIRÓ, 1975; SILVA; FIGUEIRÓ, 1980; BASILE; MIES FILHO; SELAIVE-VILLARROEL,1985). Contrario ao esperado, as ovelhas suplementadas não apresentaram taxas de parição e de partos gemelares maiores que as não suplementadas (Tabela 3). Este resultado é provavelmente um reflexo do ganho de peso que as ovelhas não suplementadas apresentaram (Tabela 2), que apesar de ser menor do que nas suplementadas, deve ter sido suficiente para um bom desempenho. Minola e Goyenechea (1975) citam um trabalho onde um grupo de ovelhas ganhou $6 \mathrm{~kg}$ e o outro perdeu 2 $\mathrm{kg}$, as percentagens de natalidade foram, respectivamente, 124 e $104 \%$, e as percentagens de partos gemelares, citados na mesma ordem, de 46 e $27 \%$, não havendo diferença na percentagem de ovelhas falhadas. Roda e Otto (1990) observaram maiores percentagens de partos gemelares em ovelhas recebendo suplementação pré-acasalamento, com médias de 30,5 e 22,0 \% para ovelhas Ideal e Corriedale recebendo $1 \mathrm{~kg} /$ dia de ração concentrada.
Tabela 5 - Médias para os pesos $(\mathrm{kg})$ dos cordeiros ao nascimento e ao desmame e para o ganho médio diário (GMD, kg) do nascimento ao desmame, segundo a época de acasalamento, o nível de suplementação alimentar, a idade, o tipo de parto e o grupo genético das mães e o sexo dos cordeiros.

\begin{tabular}{|c|c|c|c|}
\hline Efeitos & $\begin{array}{c}\text { Peso } \\
\text { Nascimento }\end{array}$ & $\begin{array}{c}\text { Peso } \\
\text { Desmame }\end{array}$ & GMD \\
\hline \multicolumn{4}{|l|}{ Época } \\
\hline Verão & $5,13 \pm 0,22 \mathrm{a}$ & $13,46 \pm 1,14$ & $0,124 \pm 0,015$ \\
\hline Outono & $4,65 \pm 0,21 b$ & $13,34 \pm 1,07$ & $0,122 \pm 0,014$ \\
\hline $\operatorname{Pr}>F$ & 0,0329 & 0,9149 & 0,9241 \\
\hline \multicolumn{4}{|l|}{ Suplementação } \\
\hline Não & $5,02 \pm 0,21$ & $13,63 \pm 1,09$ & $0,126 \pm 0,014$ \\
\hline Sim & $4,75 \pm 0,22$ & $13,17 \pm 1,12$ & $0,120 \pm 0,014$ \\
\hline $\operatorname{Pr}>F$ & 0,2212 & 0,6838 & 0,6741 \\
\hline \multicolumn{4}{|l|}{ Idade - dentes } \\
\hline 02 & $4,31 \pm 0,27 \mathrm{~b}$ & $10,55 \pm 1,37 \mathrm{~b}$ & $0,098 \pm 0,018$ \\
\hline 04 & $5,03 \pm 0,35 \mathrm{a}$ & $13,73 \pm 1,77 \mathrm{ab}$ & $0,125 \pm 0,023$ \\
\hline 06 & $5,39 \pm 0,30 \mathrm{a}$ & $14,88 \pm 1,56 \mathrm{a}$ & $0,135 \pm 0,020$ \\
\hline 08 & $4,82 \pm 0,20 \mathrm{ab}$ & $14,44 \pm 1,02 \mathrm{a}$ & $0,135 \pm 0,013$ \\
\hline $\operatorname{Pr}>F$ & 0,0216 & 0,0399 & 0,2335 \\
\hline \multicolumn{4}{|l|}{ Tipo de parto } \\
\hline Simples & $3,98 \pm 0,18 b$ & $13,58 \pm 0,92$ & $0,138 \pm 0,012$ \\
\hline Gemelar & $5,79 \pm 0,32 \mathrm{a}$ & $13,22 \pm 1,62$ & $0,108 \pm 0,021$ \\
\hline $\operatorname{Pr}>F$ & 0,0001 & 0,8416 & 0,2054 \\
\hline \multicolumn{4}{|l|}{ Grupo genético } \\
\hline Corriedale & $5,13 \pm 0,34$ & $9,83 \pm 1,73 b$ & $0,073 \pm 0,022 \mathrm{~b}$ \\
\hline Hampshire & $4,77 \pm 0,22$ & $14,02 \pm 1,12 \mathrm{a}$ & $0,137 \pm 0,014 \mathrm{a}$ \\
\hline Ile de France & $4,40 \pm 0,26$ & $12,86 \pm 1,33 \mathrm{ab}$ & $0,119 \pm 0,017 \mathrm{ab}$ \\
\hline Suffolk & $5,25 \pm 0,44$ & $16,89 \pm 2,27 \mathrm{a}$ & $0,164 \pm 0,029 \mathrm{a}$ \\
\hline $\operatorname{Pr}>F$ & 0,2265 & 0,0376 & 0,0168 \\
\hline \multicolumn{4}{|l|}{ Sexo } \\
\hline Fêmea & $4,80 \pm 0,21$ & $12,69 \pm 1,07$ & $0,116 \pm 0,014$ \\
\hline Macho & $4,98 \pm 0,22$ & $14,11 \pm 1,15$ & $0,131 \pm 0,015$ \\
\hline $\operatorname{Pr}>F$ & 0,4243 & 0,2142 & 0,3008 \\
\hline
\end{tabular}

$\mathrm{a}, \mathrm{b}-(\mathrm{P}<0,05)$

Os dados de prolificidade ao parto e ao desmame (Tabela 4) mostram tendência ( $\mathrm{P}>0,11$ e $\mathrm{P}>0,08$, respectivamente) de maior desempenho das raças de corte comparadas à Corriedale. Apesar das ovelhas Corriedale paridas terem apresentado boa taxa de partos gemelares, a taxa de parição neste grupo genético foi menor que nas ovelhas Hampshire Down e Ile de France. Da mesma forma, as ovelhas Suffolk 
não apresentaram boa taxa de parição, porém o índice de partos gemelares foi o mais alto (60\%).

Os pesos dos cordeiros ao nascimento e ao desmame (70 dias) e o ganho de peso médio diário neste período são apresentados na Tabela 5. Em cordeiros gêmeos, os pesos e ganhos são a soma dos dois cordeiros. A época de cobertura afetou apenas o peso ao nascimento dos cordeiros, onde as ovelhas que foram acasaladas no verão apresentaram cordeiros mais pesados, provavelmente em função das melhores condições da pastagem durante o período de gestação. A gestação das ovelhas acasaladas no outono ocorreu em sua maior parte no inverno, onde naturalmente há uma baixa produção e qualidade das gramíneas de crescimento estival. Apesar de não ter havido diferença no peso ao parto entre os dois grupos de ovelhas, do início da suplementação ao parto, as ovelhas acasaladas no verão ganharam em média $6,1 \mathrm{~kg}$ e as no outono $2,8 \mathrm{~kg}$, refletindo a melhor condição alimentar do primeiro grupo.

Não houve diferença para os pesos ao nascimento, desmame e para o ganho médio diário dos cordeiros entre ovelhas suplementadas ou não, porém cordeiros nascidos de ovelhas de 2 dentes foram significativamente mais leves ao nascimento e ao desmame (Tabela 5). Fato este esperado, pois as borregas foram mais leves, encontrando-se ainda em fase de desenvolvimento, e provavelmente produzindo menos leite. Segundo Minola e Goyenechea (1975), há um aumento na produção leiteira da primeira até a quarta lactação.

O peso total (soma dos dois cordeiros) ao nascimento dos cordeiros gêmeos foi maior do que os únicos, não havendo diferenças no ganho médio diário e no peso ao desmame (Tabela 5), porém se contabilizarmos os pesos individuais, podemos verificar que os gêmeos foram $27,3 \%$ mais leves ao nascimento e 51,3\% mais leves ao desmame. Os cordeiros dos grupos genéticos Suffolk e Hampshire
Down ganharam significativamente mais peso e foram mais pesados ao desmame que os cordeiros filhos de ovelhas Corriedale, sendo que os do grupo Ile de France apresentaram ganhos e pesos intermediários e não diferiram dos outros três grupos. Não houve diferença entre os sexos para os pesos ao nascimento, ao desmame e para o ganho médio diário até o desmame. Até os 100 a 120 dias de idade normalmente não é encontrada diferença significativa nos pesos de cordeiros e cordeiras (FIGUEIRÓ; BENAVIDES, 1990; CARVALHO et al., 1997).

Roda, Santos e Cunha,(1995) observaram em cordeiros Ideal e Corriedale que os pesos ao nascimento e ao desmame foram influenciados pela raça, pelo sexo do cordeiro, onde os machos foram mais pesados, pelo ano de nascimento e pela idade da ovelha. Cordeiros filhos de borregas e de ovelhas com sete ou mais anos foram mais leves.

Nos resultados apresentados na Tabela 6 pode se verificar que a única diferença significativa observada é a maior quantidade de quilos de cordeiros desmamados por quilo de ovelha parida no grupo suplementado. Porém, o melhor índice de produtividade é o que considera todas as ovelhas acasaladas, ou seja, quilos de cordeiros desmamados por quilo de ovelha acasalada, não sendo encontrado diferença significativa entre os grupos suplementado e não suplementado para este índice, assim como não foi encontrada diferenças para as demais variáveis estudadas. Ovelhas com cordeiros únicos tenderam $(\mathrm{P}=0,0523)$ a produzir mais quilos de cordeiros por ovelha parida do que ovelhas com gêmeos, o que pode ser atribuído a maior mortalidade dos cordeiros gêmeos. De maneira similar, ovelhas do grupo Suffolk tenderam $(\mathrm{P}=0,0649)$ a produzir mais quilos de cordeiros por ovelha parida do que ovelhas dos grupos Corriedale, Hampshire Down e Ile de France. 
Tabela 6 - Médias para produtividade de ovelhas de acordo com a época de acasalamento, o nível de suplementação alimentar, a idade, grupo genético e tipo de parto da ovelha, e o sexo dos cordeiros.

\begin{tabular}{|c|c|c|}
\hline Efeitos & $\begin{array}{c}\text { Kg de cordeiros desmamados / } \\
\text { kg de ovelhas acasaladas }\end{array}$ & $\begin{array}{c}\mathrm{Kg} \text { de cordeiros desmamados } \\
\mathrm{kg} \text { de ovelhas paridas }\end{array}$ \\
\hline \multicolumn{3}{|l|}{ Época } \\
\hline Verão & $0,27 \pm 0,02$ & $0,30 \pm 0,02$ \\
\hline Outono & $0,26 \pm 0,02$ & $0,29 \pm 0,02$ \\
\hline $\operatorname{Pr}>F$ & 0,9616 & 0,4316 \\
\hline \multicolumn{3}{|l|}{ Suplementação } \\
\hline Não & $0,26 \pm 0,02$ & $0,28 \pm 0,02 \mathrm{~b}$ \\
\hline Sim & $0,27 \pm 0,02$ & $0,31 \pm 0,02 \mathrm{a}$ \\
\hline $\operatorname{Pr}>F$ & 0,5899 & 0,0493 \\
\hline \multicolumn{3}{|l|}{ Idade - dentes } \\
\hline 02 & $0,25 \pm 0,03$ & $0,29 \pm 0,02$ \\
\hline 04 & $0,24 \pm 0,04$ & $0,28 \pm 0,03$ \\
\hline 06 & $0,29 \pm 0,03$ & $0,32 \pm 0,02$ \\
\hline 08 & $0,27 \pm 0,02$ & $0,31 \pm 0,01$ \\
\hline $\operatorname{Pr}>F$ & 0,7442 & 0,4485 \\
\hline \multicolumn{3}{|l|}{ Grupo } \\
\hline Corriedale & $0,24 \pm 0,04$ & $0,27 \pm 0,02$ \\
\hline Hampshire & $0,27 \pm 0,02$ & $0,28 \pm 0,02$ \\
\hline Ile de France & $0,27 \pm 0,03$ & $0,27 \pm 0,02$ \\
\hline Suffolk & $0,28 \pm 0,05$ & $0,37 \pm 0,03$ \\
\hline$P R>F$ & 0,8127 & 0,0649 \\
\hline \multicolumn{3}{|l|}{ Tipo de parto } \\
\hline Simples & $0,29 \pm 0,02$ & $0,32 \pm 0,01$ \\
\hline Gemelar & $0,23 \pm 0,04$ & $0,27 \pm 0,02$ \\
\hline $\operatorname{Pr}>\mathrm{F}$ & 0,1451 & 0,0523 \\
\hline \multicolumn{3}{|l|}{ Sexo } \\
\hline Fêmea & $0,25 \pm 0,03$ & $0,30 \pm 0,02$ \\
\hline Macho & $0,28 \pm 0,02$ & $0,29 \pm 0,02$ \\
\hline $\operatorname{Pr}>F$ & 0,3141 & 0,5904 \\
\hline
\end{tabular}

$\mathrm{a}, \mathrm{b}-(\mathrm{P}<0,05)$

\section{Conclusões}

Na região norte do Paraná as ovelhas estão aptas à reprodução no verão e no outono, podendo ser utilizada qualquer uma das duas épocas de acasalamento.

Em pastagens de boa qualidade, que permita ganho de peso às ovelhas, é desaconselhado a suplementação alimentar.

Cordeiros nascidos como gêmeos são, individualmente, mais leves e apresentam maior mortalidade até o desmame. Desta forma, o maior número de partos gemelares só é vantajoso se os cordeiros tiverem um bom peso ao nascimento, e se a ovelha possuir uma boa habilidade materna, para diminuir a mortalidade e melhorar os pesos ao desmame.

\section{Referências}

BASILE, B. H.; MIES FILHO, A.; SELAIVEVILLARROEL, A. B. Indução da atividade sexual em ovelhas Corriedale mediante controle da luminosidade. Semina, Londrina, v.6, n.3, p.125-132, 1985.

BOUKHLIQ, R.; ADAMS, N. R; MARTIN, G. B. Effect of nutrition on the balance of production of ovarian and pituitary hormones in ewes. Animal Reproduction Science, Amsterdam, v.45, n.1-2, p.59-70, 1996.

BRADFORD, G.E. Selection for litter size. In: LAND, R.B.; ROBINSON, D.W. Genetics of reproduction in sheep. London: Butterworths, 1985. p.3-17.

CARVALHO, S. et al. Confinamento de cordeiros machos inteiros, castrados e fêmeas abatidos aos 100 dias de idade. In: REUNIÃO ANUAL DA SOCIEDADE BRASILEIRA DE ZOOTECNIA, 34., 1997, Juiz de Fora. Anais... Viçosa: Soc. Bras. Zootec., 1997. CD-Rom.

COIMBRA FILHO, A. Técnicas de criação de ovinos. 2.ed. Guaíba: Agropecuária, 1997.

CORRÊA, A.R.; GODOY, H.; BERNARDES, L.R.M. Características climáticas de Londrina. Londrina: IAPAR, 1982. $16 \mathrm{p}$.

ELSEN, J.W. et al. Genetic improvement of litter size in sheep. In: WORLD CONGRESS ON GENETICS APPLIED TO LIVESTOCK PRODUCTION, 5., 1994. Guelph. Proceedings... Guelph, Canada: University of Guelph, 1994. v.19 ,p.237-244.

FIGUEIRÓ, P.R.P.; BENAVIDES, M.V. Produção de carne ovina. In: Caprinocultura e ovinocultura. Piracicaba: Soc. Bras. Zootec., 1990. p.15-31.

MIES FILHO, A.; RAMOS, A.A. Ciclo estral de ovelhas no Brasil. Revista da Escola de Agronomia e Veterinária da UFRGS, Porto Alegre, v.3, p.57-63, 1960.

Verificação do comportamento sexual de carneiros no Brasil. Bagé: EMBRAPA/CNPO, 1987. 197 p.

MINOLA, J.; GOYENECHEA, J. Praderas \& lanares: Producción ovina en alto nivel. Montevidéo: Hemisfério Sur, 1975. 365 p.

NUNES, J.F.; FIGUEIRÓ, P.R.P. Fatores que afetam o comportamento reprodutivo em ovelhas Corriedale e 
Polwarth. Revista Centro Ciências Rurais, Santa Maria, v.5, n.4, p.301-307, 1975.

ORTOLONI, E.L.; SIQUEIRA, E.R. Aprenda a criar ovinos. São Paulo: Nobel, 1986.

RIBEIRO, E.L.A. et al. Aspectos reprodutivos em ovelhas Hampshire Down submetidas a monta contínua na região norte do Paraná. Revista da Sociedade Brasileira de Zootecnia, Viçosa, v.25, n.4, p.637-646, 1996.

RIBEIRO, E.L.A et al. Efeito de coberturas iniciadas na primavera ou no verão sobre o desempenho reprodutivo de ovelhas. Semina, Londrina, v.20, n.1, p.39-43, 1999.

RODA, D.S.; OTTO, P.A. Efeito da suplementação alimentar pré-acasalamento na prolificidade de ovinos das raças Ideal e Corriedale. Boletim de Indústria Animal, Nova Odessa, v.47, n.2, p.87-96, 1990.

RODA, D.S. et al. Efeito do tipo de gestação (simples ou gemelar) na sobrevivência e desenvolvimento de cordeiros das raças Ideal e Corriedale. Boletim de Indústria Animal, Nova Odessa, v.47, n.2, p.115-119, 1990.

RODA, D.S. et al. Desempenho de ovinos em sistema de acasalamento a cada oito meses. Boletim de Indústria Animal, Nova Odessa, v.50, n.1, p.49-54, 1993.

RODA, D.S.; SANTOS, L.E.; CUNHA, E.A. Peso ao nascer e mortalidade pré-desmame em cordeiros das raças Ideal e Corriedale. Boletim de Indústria Animal, Nova Odessa, v.52, n.1, p.67-70, 1995.

SAS INSTITUTE. SAS/STAT User's Guide. Cary: SAS Institute Inc., 1994. v.2.
SELAIVE-VILLARROEL, A.B. Principais aspectos no manejo ovino durante a parição.. Bagé: EMBRAPA/ UEPAE, 1979. (Comunicado Técnico).

SELAIVE-VILLARROEL, A.B. Considerações básicas em uma criação de ovinos. Bagé: EMBRAPA/UEPAE, 1984. 32 p.

SELAIVE-VILLARROEL, A.B. Manejo reprodutivo dos ovinos. In: SIMPÓSIO PARANAENSE DE OVINOCULTURA, 3, 1986, Guarapuava. Anais... Guarapuava: OVINOPAR, 1986. p.62-71.

SILVA, O.L.; FIGUEIRÓ, P.R.P. Efeito da época de cobertura sobre a fertilidade de ovelhas e mortalidade de cordeiros na raça Corriedale. In: REUNIÃO ANUAL DA SOCIEDADE BRASILEIRA DE ZOOTECNIA, 27, 1980, Fortaleza. Anais... Viçosa: Soc. Bras. Zootec., 1980. p. 127 .

SIQUEIRA, E.R. Raças ovinas e sistemas de produção: produção de ovinos. In: CONFERÊNCIA ANUAL DA SICIEDADE PAULISTA DE MEDICINA VETERINÁRIA, 45.,1990, Jaboticabal. Anais... Jaboticabal: FUNEP, 1990. p.1-25,

THOMAS, D.L. et al. Effects of plane of nutrition and Phenobarbital during the pre-mating period on reproduction in ewes fed differentially during the summer and mated in the fall. Journal of Animal Science, Ottawa, v.64, p.1144-1152, 1987.

VILLAS BOAS, A. S. Instalações e manejo do rebanho ovino. Produção de ovinos. Anais... Jaboticabal: FUNEP, p.27-64, 1990. 